\title{
System requirements for a computerised patient record information system at a busy primary health care clinic
}

\author{
PJ Blignaut, Ph.D, Department of Computer Science and Informatics, UFS \\ T McDonald, Ph.D, Department of Computer Science and Informatics, UFS \\ CJ Tolmie, Ph.D, Department of Computer Science and Informatics, UFS
}

\section{Abstract}

A prototyping approach was used to determine the essential system requirements of a computerised patient record information system for a typical township primary health care clinic. A pilot clinic was identified and the existing manual system and business processes in this clinic was studied intensively before the first prototype was implemented. Interviews with users, incidental observations and analysis of actual data entered were used as primary techniques to refine the prototype system iteratively until a system with an acceptable data set and adequate functionalities were in place. Several non-functional and user-related requirements were also discovered during the prototyping period.

\section{Samevatting}

' $n$ Prototiperingsbenadering is gevolg om die essensiële stelselvereistes van ' $n$ gerekenariseerde pasiëntrekordstelsel vir "n tipiese "township" primêre gesondheidsorgkliniek te bepaal. " $n$ Loodskliniek is geïdentifiseer en die bestaande handstelsel en besigheidsprosesse in dié kliniek is deeglik bestudeer voor die eerste prototipe geïmplementeer is. Onderhoude met gebruikers, toevallige waarnemings en ontleding van werklike gestoorde data is as primêre tegnieke gebruik om die prototipestelsel iteratief te verfyn totdat dit oor ' $n$ aanvaarbare datastel en voldoende funksionaliteite beskik het. Verskeie nie-funksionele en gebruikersverwante vereistes is ook ontdek gedurende die prototiperingstydperk.

\section{Introduction}

"As professional nursing moves to meet the challenges of a second millennium, extensive nursing information systems are required. Nursing information systems of the future must do more than simply support various tasks. They must provide strategic resources for clinical nursing practice. These systems must be data-driven and nurses must make decisions about their design, development and evaluation" [Manning \& McConell, 1997:141].

Today's nurses are faced with serious problems of providing care to patients with increasingly complex conditions in a shorter period of time as well as administrative pressures to improve productivity and quality. Sorrentino [1991:23] advocates that automation can provide them with an opportunity to direct their time and effort to meaningful patient care. Tedious administrative tasks can be eliminated using computerisation. According to Neame [1995:4-6] the benefits of an electronic medical record are numerous. Information is available from every computer that is connected to the database and entries made by multiple providers in different locations can be linked to create a single record for an individual. Data can be checked as it is entered to ensure adequacy and accuracy. The same data can be viewed in different ways and links to knowledgebased tools are also possible.

Adderley et. al. [1997:45] maintain that "computerisation has allowed more time for personalised patient care and patient/ staff interaction". They also concluded that "it (computerisation) has made information readily available for acquisition and analysis of data".

Anderson et. al. [1995:767] also argue that a computer-based patient record could improve health care in several important ways. It could provide practitioners with rapid access to more reliable patient data. It could also support clinical decision making, clinical reminders and alerts, quality assurance and outcomes research.

When a health information system is computerised, the worldwide trend is to combine the statistical processing with the patient record system into a single health information system [Leske et.al. 1992:260: Neame, 1995:11; Pulliam, 1992:123; Wallace, 1994:1]. Such a system will keep a permanent record of individual patients and simultaneously increment the number of cases without the service provider even being aware of it. At regular intervals the statistical data will be summarised and presented in a format that will be useful to both the service providers and nursing management at regional, provincial and national level.

In previous studies the author has examined the effects of computerisation on primary health care specifically in South African townships. The automatic capturing and processing of statistics seemed to be the single most important aspect that would alleviate nurses' administrative workload [Blignaut $\&$ Mc Donald, 1997(1):122; Blignaut \& Mc Donald, 1997(2):27]. Despite these presumed and proven benefits of the computerisation of health care, the process is not without its pot-holes and computerisation of primary health care specifically should 
be approached with caution. The current study is an attempt to determine the system requirements of a computerised patient record information system for primary health care clinics. Some of the lessons learnt regarding the development and implementation of such a system in a pilot clinic is also discussed. The results of this study could be used as a starting point for health authorities when contracting system developers to develop a patient record information system for primary health care.

\section{Methodology}

The processes that were used to determine the functional requirements of a computerised patient record information system are discussed here. These processes should not be seen as a series of steps that were executed sequentially, nor are they necessarily mutually exclusive. Furthermore, each process involved several techniques such as prototyping, interviews, and surveys.

\section{Selection of a pilot clinic}

The community health centre of the Mangaung-University of the Orange Free State Community Partnership Program (MUCPP) agreed to act as a pilot site. This clinic has been used for previous studies [McDonald \& Blignaut, 1998:8-13] and was ideally suited for this study as well. It is a typical busy township clinic and serves about 500,000 people from an underprivileged community.

The MUCPP clinic can be regarded as representative of typical primary health care clinics in township areas. The most of the permanent staff members were from an African culture with no previous computer experience. The services provided included all basic primary health care services. The patient throughput per service provider per day was actually more than in the most other clinics $( \pm 30$ patients per nurse per day).

\section{Definition of the data set}

The data set forms the basis of any software system [Hettinger, 1992:112]. The data set should comprise all the essential data elements without being over-comprehensive. All documentation of the current manual system at the pilot clinic was studied to determine an initial data set. These include all kinds of patient cards, files, tally sheets, reports on statistics, etc. Completed records, not blank cards and files, were used. Potential users (nursing staff as well as clerical workers) were interviewed and observed while at work [Shneiderman, 1998:145]. Many of the requirements were discovered incidentally rather than formally.

The data set was documented as an entity-relationship diagram. Microsoft Access $®$ proved to be a good, though inexpensive and readily available, tool that could be used to document the data set and define relationships between entities.

\section{A study of the business processes}

A primary health care clinic has a fixed routine. Answers to each one of the following questions were obtained by studying the current manual system and interviewing the potential users.

- Where are the patients registered?

- How are patients identified?

- Where do the patients spend the time waiting?

- What primary health care services does the clinic cater for?

- Where are special investigations such as urine and blood tests done?

- Where are the consultations done?

- How are consultations done? Is there a specific protocol according to which consultations are done?

- How are referrals handled?

- Where are follow-up treatments such as dressings done?

- How are statistical reports compiled?

- Where is medicine handed out?

- How is stock control done?

- Where are the patient files stored? How are they

filed?

\section{Figure 1 : Curatives screen in the first prototype (Patient name removed for privacy purposes)}

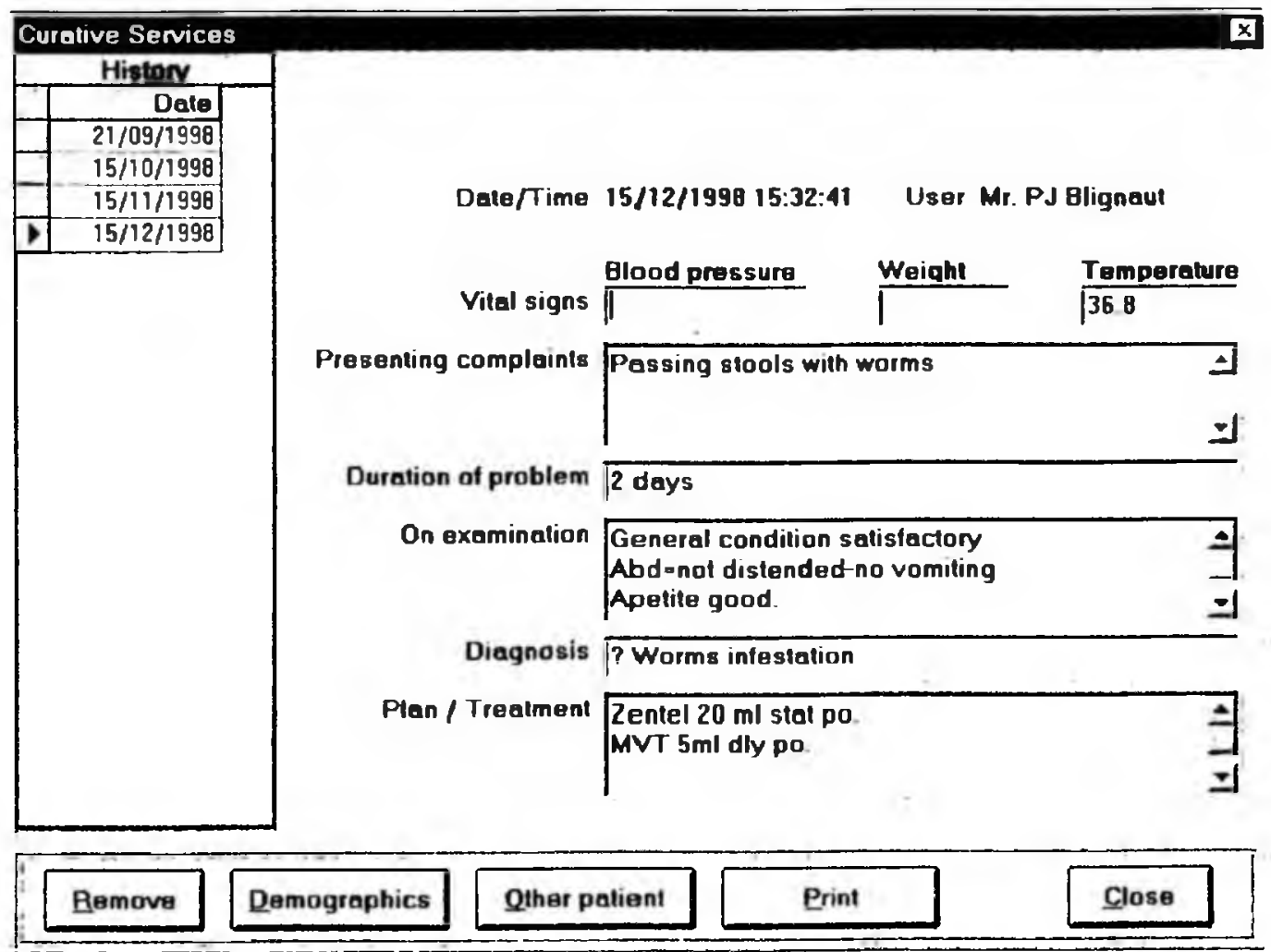


Figure 2 : On-line suggestion box

\section{SUGGESTION BOX}

Your suggestions will be highly appreciated. If you

want to. you can add your name.

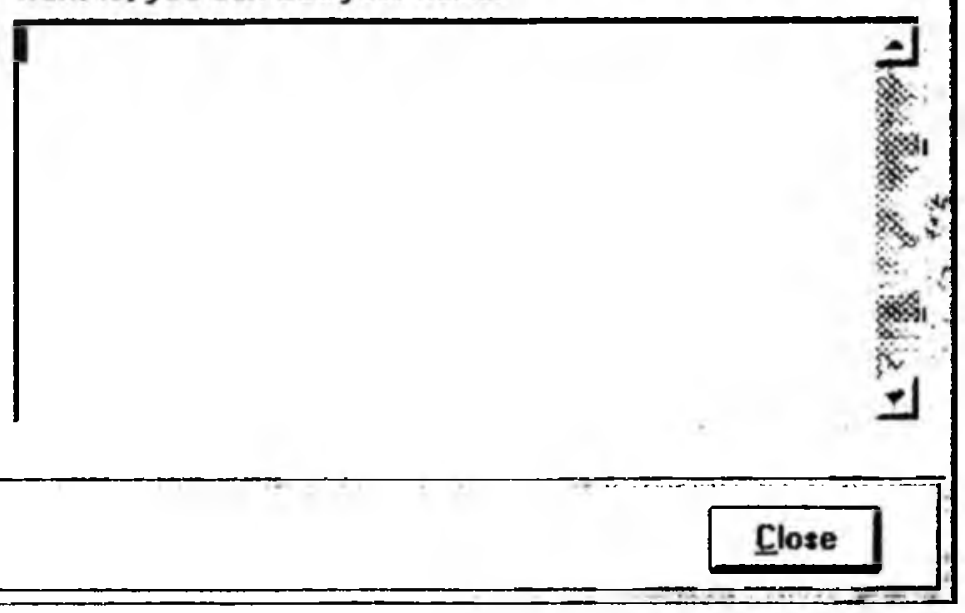

\section{Use of a prototyping approach}

The basic principle of evolutionary prototyping [Sommerville, 1995:142] was followed. The idea was to develop an initial implementation, expose it to the users and refine it iteratively until an adequate system were developed.

The first prototype (figure 1) was nothing more than a set of on-screen replicas of the manual system's forms and cards, but sufficed as a tool for discovering the format and contents of typical data entries made by nurses in a real-world situation. It was accepted that it is unreasonable to expect that service providers must remember everything about their daily tasks while they are interviewed or while they complete a questionnaire.

A modular, depth-first approach was followed. The prototypes implemented the services provided at primary health care level as separate modules. For example, separate modules catered for minor ailments, antenatal care, child health, and chronic diseases such as hypertension, diabetes, and tuberculosis.

The computerised system was phased in gradually. Novice users had the opportunity to opt for the manual system in periods of peak workload when they felt that they were still too slow with the computerised system.

\section{Obtaining users' feedback}

A continuous presence was maintained at the pilot clinic for at least two months. It was our experience that users had the confidence to be frank enough to tell about shortcomings in the prototypes only after a good working relationship was established.

Users were given ample opportunity (more than three months) to discover their needs. It is generally accepted that novice or first-time users mostly blame their own inexperience for the problems that they encounter. Only after about a month were they able to identify shortcomings in the prototype systems.

Besides the fact that one of the researchers or an assistant was always present, an on-line suggestion box (figure 2) was also included in the prototypes where users could enter suggestions as they were discovered. The data entered by users during actual interventions was an invaluable source of information to give clues about the contents and format of typical data entries. Hundreds of stored patient records were studied in detail and with great care.

\section{Results and}

\section{recommendations}

\section{The data set}

Figure 3 shows the data set that was implemented for the minor ailments module in the last prototype patient record system.

\section{Functional requirements}

Functional requirements describe a system's services or functions, how the system should react on particular inputs and how the system should behave in certain situations [Sommerville, 1995:118].

The following generic tasks were identified for a system that should support the daily tasks of staff in a primary health care clinic:

- Registration of patients' demographical data.

- Recording of medical intervention, i.e. consultation details, results of special investigations, conditions diagnosed, treatments, etc.

- Capturing and processing of statistical indicators.

- Stock control

\section{Figure 3 : Data set for the minor ailments module as defined in Microsoft Access $\$$}

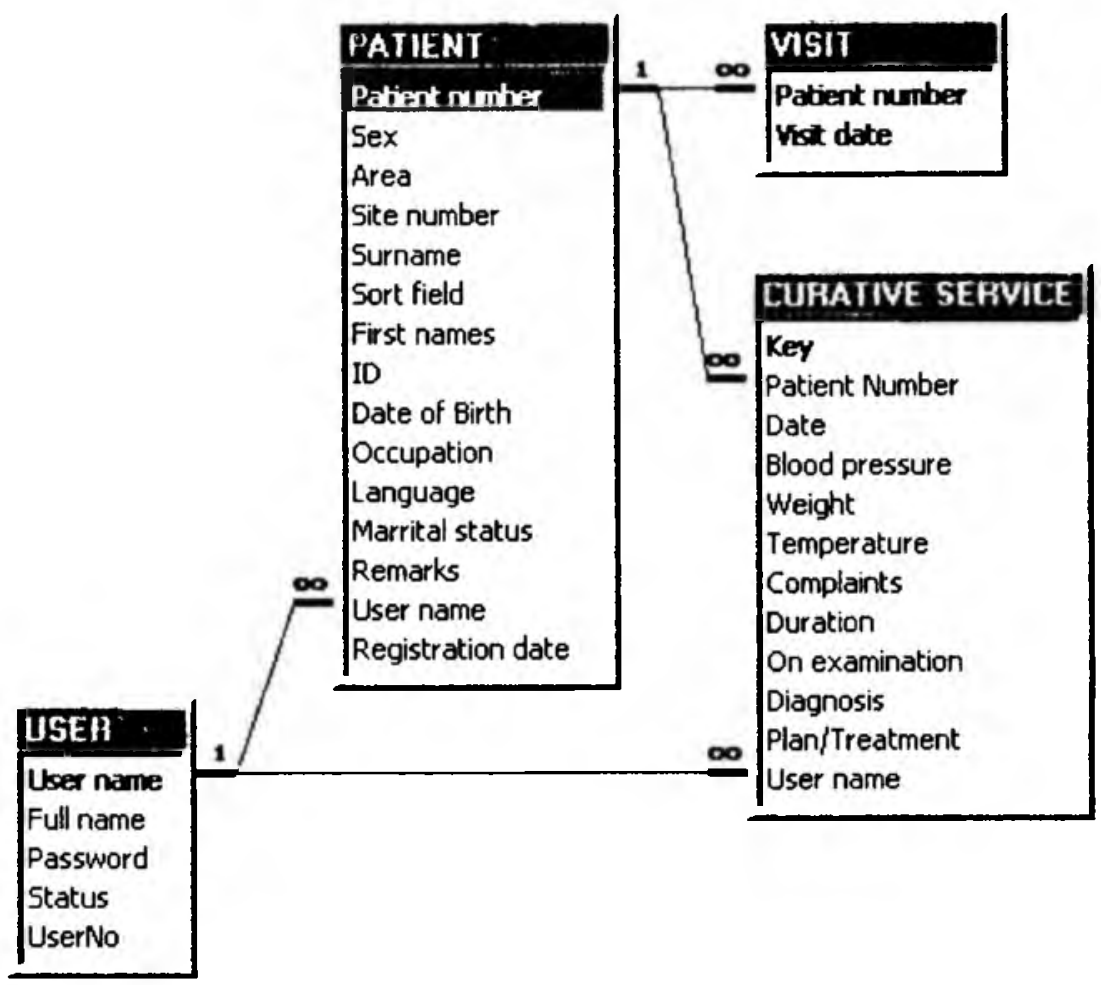




\section{DEYOTRAPHIC DETALS}

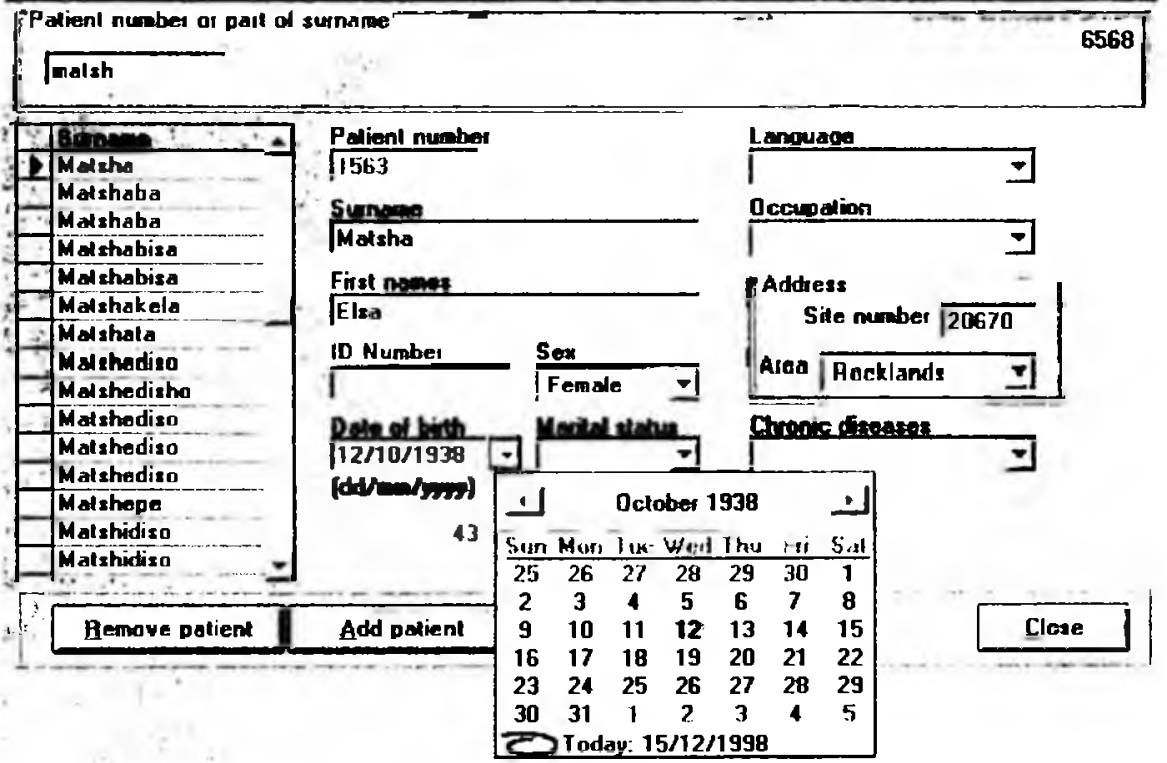

Recording of medical interventions

The system should make provision for all services provided at the clinic. It should be modular and flexible in that it should be possible to implement only relevant modules at a specific venue [Mandil, 1995:4]. For example, there should be separate modules for minor ailments, antenatal care, child health, chronic diseases such as hypertension, diabetes, tuberculosis, etc.

It was found that nurses are sensitive to the fact that a computerised system should not encroach upon their professional status. It should not make decisions for them, but rather guide them through the decision making process.

System evaluators should ascertain themselves that a software system supports the protocols that service providers are used to. The protocols should reflect the local circumstances. Nurses should not be forced

Summarising reports on all data captured.

\section{Patient registration}

The system should make provision for a way to identify every patient uniquely. In the prototypes used for the current study a unique patient number was generated automatically for every new patient registered. This number was written on the patient's file and therefore it was available on subsequent visits as well. A search on a patient's surname could also be done on subsequent visits to obtain the number.

It might be a good idea to use a person's identity number to identify him uniquely, especially in the ideal situation where all the clinics in a municipal area are connected to the same database. This would also minimise the well-known problem of clinic hopping - patients wandering from clinic to clinic to obtain free medicine and use it in an uncontrolled way.

The system should make adequate provision for search facilities on the database. It should at least be possible to trace a patient on his patient number, surname or address. The system should not enforce correct spellings on searches.

In order to facilitate summarised statistical reports, it is essential to record a patient's date of birth, gender, occupation and home language. Only users with the necessary access rights should be able to remove a patient's record from the database. Updates such as change of address should be possible. It should be possible to trace all entries and updates with regard to date and time and user.

The patient registration screen that was implemented in the prototypes in the current study is shown in figure 4 .

\section{Figure 5 : Input screen for curative details, showing the list of possible data entries}

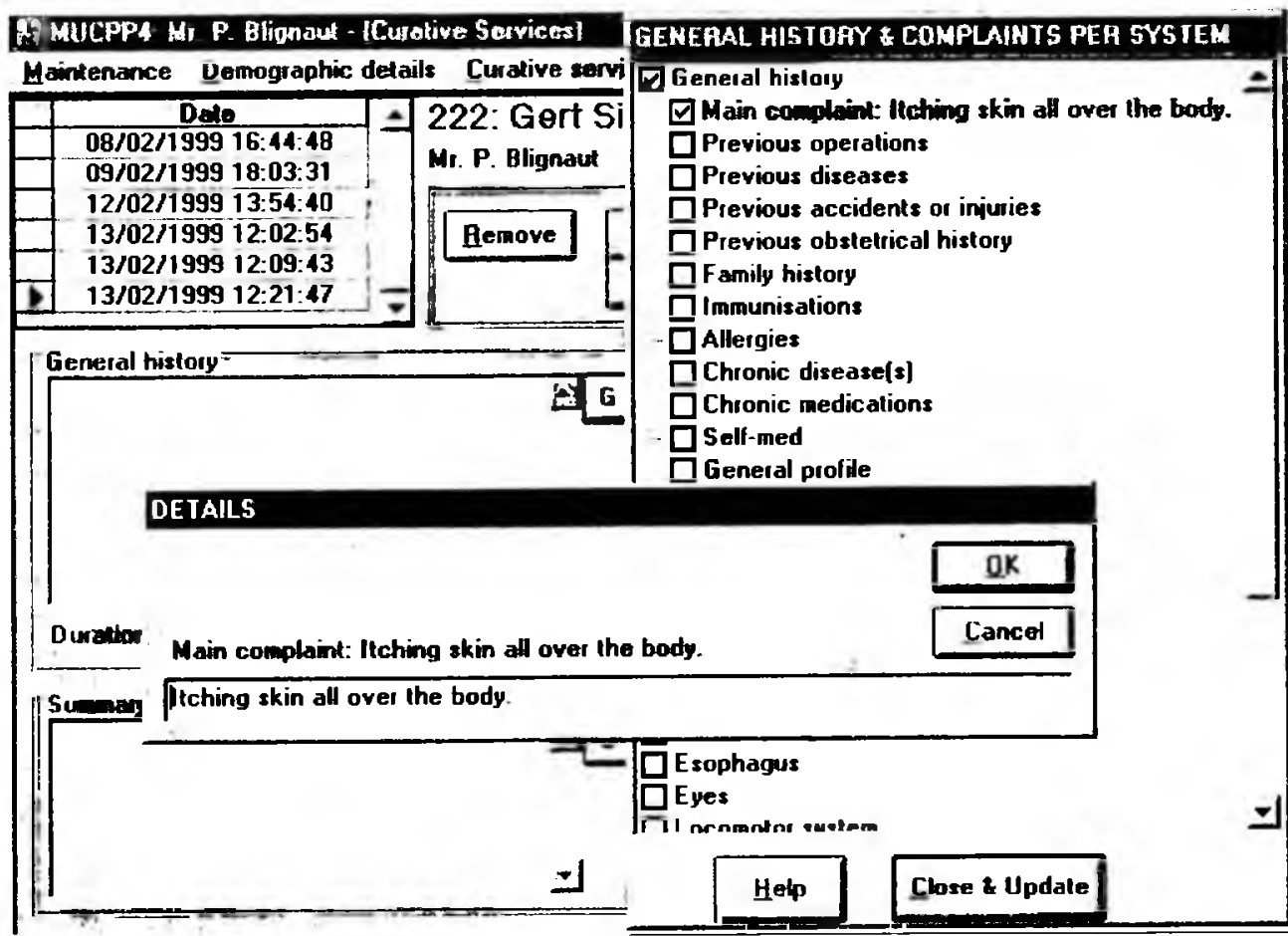




\section{PLAN / TAEATMENT}

$\mid$\begin{tabular}{l}
\multicolumn{1}{c|}{$\begin{array}{c}\text { List all slock fist for selected } \\
\text { diagnoses only }\end{array}$} \\
Amoxil \\
Counselling \\
Disprin \\
Dolorol \\
DPH \\
Mist Tussi \\
Panado \\
Refer to \\
Sputum bottles \\
To come back
\end{tabular}
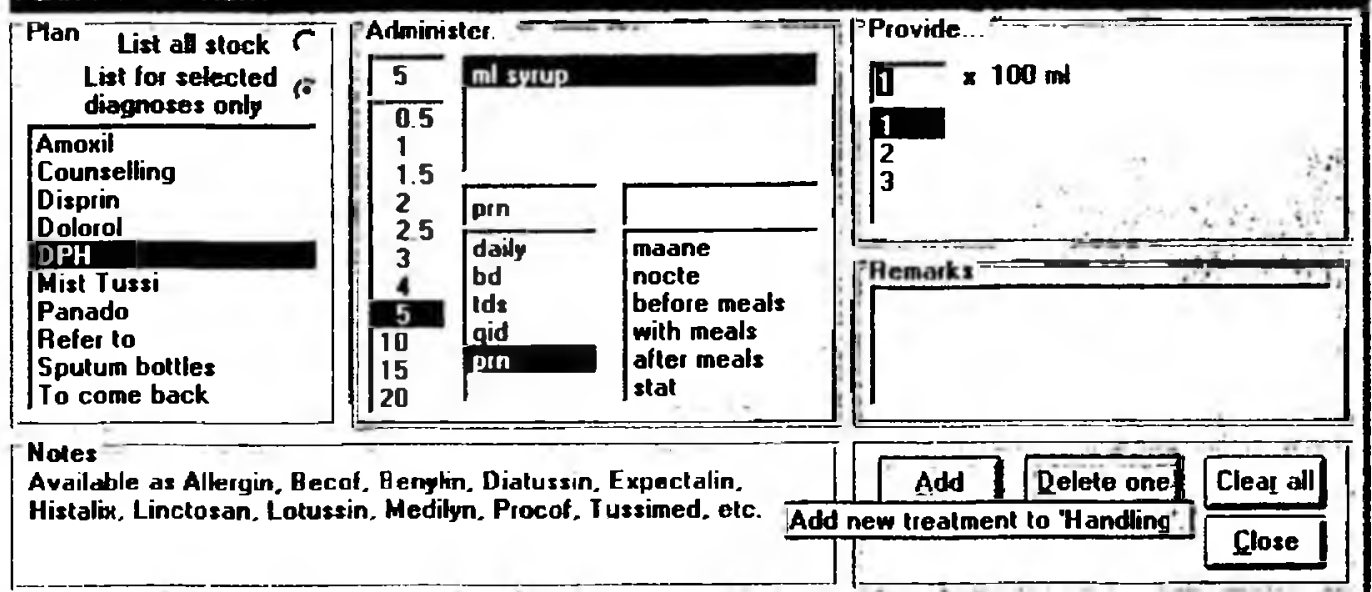

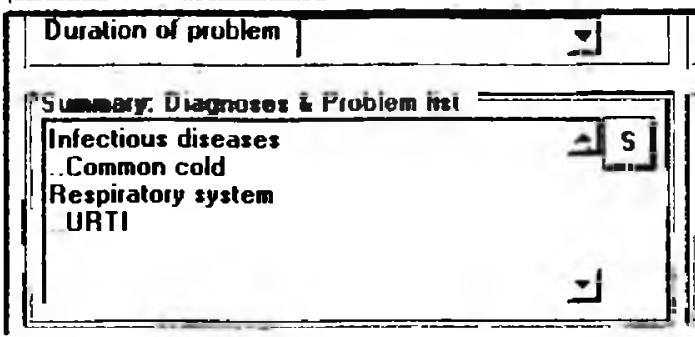

are familiar with. See the example of treatments in figure 6.

Lists should be accurate and complete - users experience immense frustration if items that should be in a list are not there. Users with the necessary access rights should be able to update lists' contents (see example in figure 7).

\section{Capturing, processing and reporting of statistics}

On screen capturing of statistics should be quick and easy and not divert the user's attention off the main task, i.e. attending to a patient. Items listed should be organised in a way that is familiar and natural to the users. Figure 8 shows how such a list might look like. Users with the necessary access rights should be able to update lists' contents as new requests for information are encountered.

One of the main reasons why service providers tend to neglect statistics to a large extent is the lack of feed back from the health authorities. Service providers cannot be expected to do a tedious task if they don't benefit from it themselves. Therefore, an information system should provide versatile and easy to use reports that fulfil in the needs of both ground level staff and health authorities. An example of such a report is shown in figure 9.

\section{Stock control}

According to the policy of health for all the South African government has granted that certain basic medicines can be provided free of charge to patients who are not members of a medical aid fund. In order not to make misuse of this privilege, extensive stock control is essential.

In order to prevent unauthorised handouts of medicine, the information system

\section{Figure 7 : Definition of treatments and strengths}

s.

should automatically subtract stock after it has been prescribed by a legitimate health care service provider. The system should also comprise adequate security levels to guard against unauthorised changes of stock levels. Users with the necessary access rights should be allowed to enter new stock and define standard dosages, prescription units and stock levels (see figure 7).

\section{Reporting}

An information system is ideally a tool that takes raw input data and converts it to usable information. This information should be presented in a usable and meaningful way. Reports generated should be easy to use, though versatile and compre-

hensive.

Reports such as depicted in figure 10 provide users with the ability to filter records both horizontally and vertically. This means that users can select to display only a subset of records as well as a subset of fields. Users can also decide on the sorting order of records displayed. Reports on statistics such as those depicted in figure 9 also provide users with the facility to count occurrences in groups. Reports structured in this way are easy to define though they present enough information to aid both ground level staff and health authorities in the decision-making processes.

It should be possible to produce printed copies of all reports.

\section{Non-functional requirements}

Non-functional requirements define system properties and constraints [Sommerville, 1995:130]. Examples of system properties are reliability, response times and store occupancy. The

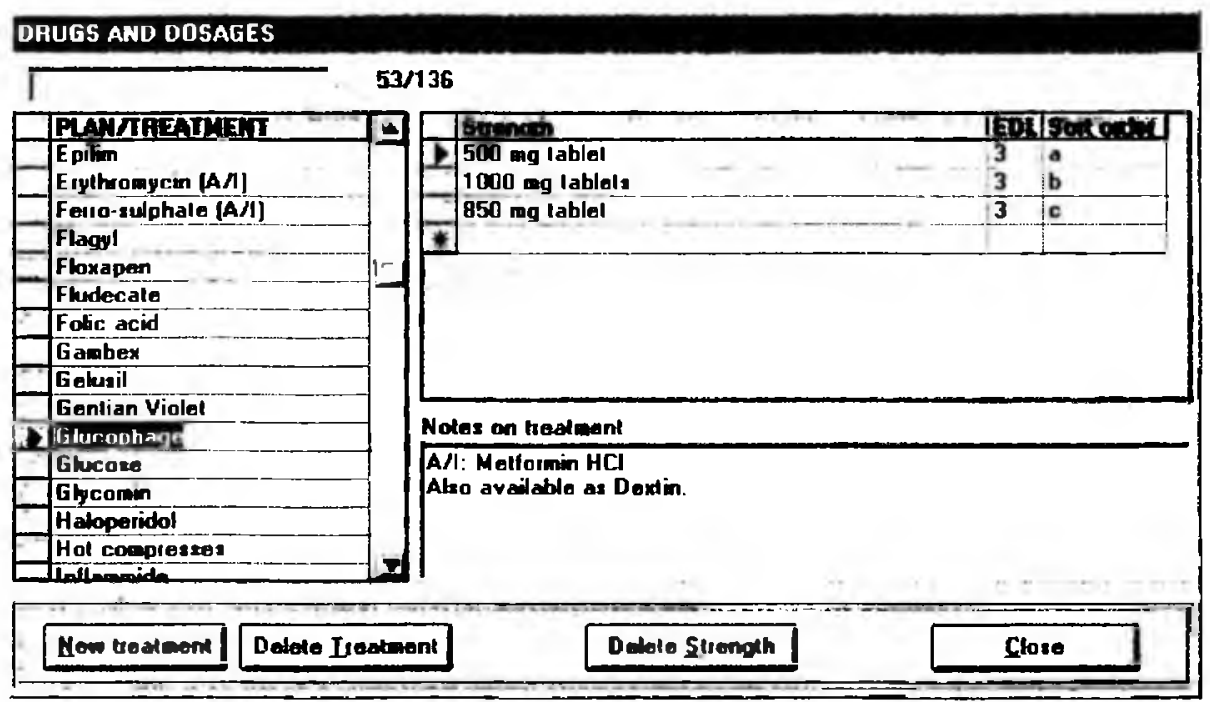




\section{Figure 8 : List to capture} basic statistics

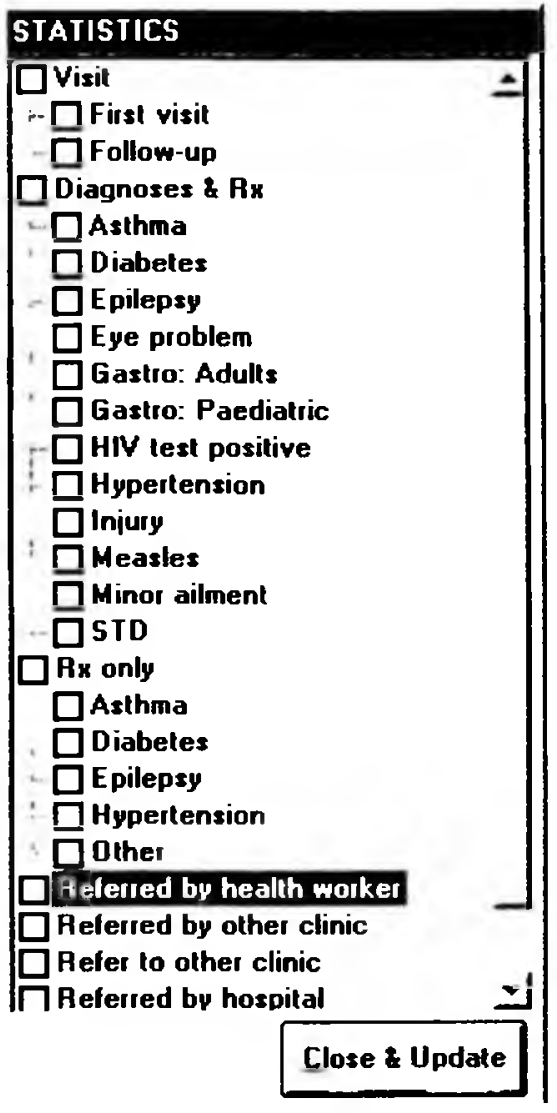

capabilities of the hardware devices attached to the system are system constraints. Some of the most crucial aspects for a primary health care setting are discussed below.

\section{Connectivity}

In the current study a peer-to-peer local area network was established to connect the computers of 10 health care service providers, 2 computers in the reception office and 1 computer in the dispensary. This ensured that a patient's complete record was accessible from anywhere in the clinic.

Although it was not the case, in this study, it is preferable that all clinics in at

least the same municipal area are connected to the same database server. The availability of a person's medical record at each clinic will enable service providers to have a complete patient record of every patient, regardless of which clinic is attended.

\section{Equipment}

It is important to acquire the best possible equipment with the available funds. In the current study we were largely dependent on donations and we experienced some frustration with inadequate equipment. Cheap equipment caused slow response times and unreliable network connections. We recommend that a system that runs in a Windows 95 (or later) environment should run on a CPU speed of at least $300 \mathrm{MHz}$ and internal memory of at least $16 \mathrm{MB}$ (preferably $32 \mathrm{MB}$ ). Since the database resides on a server, the hard disk space on the workstations is not critical.

It is important to use quality network cards to ensure a reliable network. Co-axial cabling might be cheap but the risk exists that one bad link can let the whole network down. We found that a hub, capable of handling at least 10Mbps, and UTP cabling is preferable for a local area network.
A peer-to-peer network operating system such as that provided by Windows 95 or later would handle up to 15 computers well enough. In larger clinics with more computers a dedicated server running an enterprise network operating system such as Novell NetWare would be preferable.

\section{Safety and Security}

It was found in the current study that ignorant users, especially doctors, tend to tamper with the computers' configurations, thus causing frustration for the next user who could not get access to the network or database. The peer-to-peer networking as offered by Windows provides little security and it is essential that a means exist to restrict users from tampering. The clerical worker who acted as on-site system manager had his hands full to reset computers' configurations on a regular basis.

The need for an investment into a good anti-virus system is self-explanatory. The anti-virus software should also be updated regularly - at least twice per year.

If a local area network is used, it is essential to ensure that the database server is kept in a safe place against theft. Insurance can replace a computer but not the data that was saved on the hard drive. In the current study the computer in the dispensary was used to serve as primary database server since it was locked up at all times behind iron security bars.

The software should dispose of a facility to backup the database regularly to a separate computer that is kept in another room. In the current study, one of the computers in the reception office was used as secondary database server.

A stable power supply should be ensured and mechanisms should be provided to prevent people from accidentally switching off the power. This is especially important for the database server. We experienced tremendous problems in the winter when heaters caused frequent power failures. We solved the problem by establishing a separate circuit and circuit breaker for the computer equipment.

\section{Figure 9 : Report form of summarising statistics}

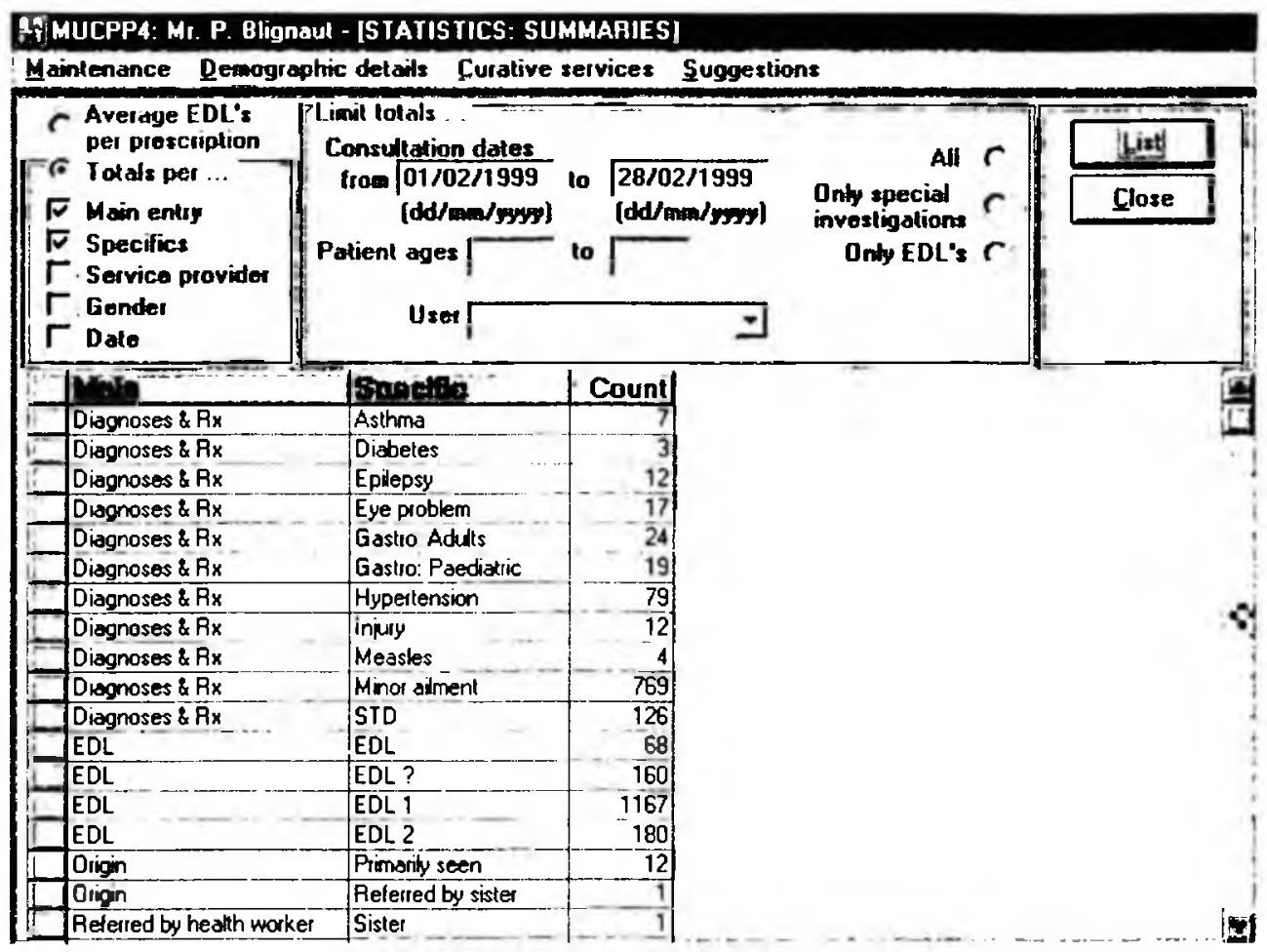




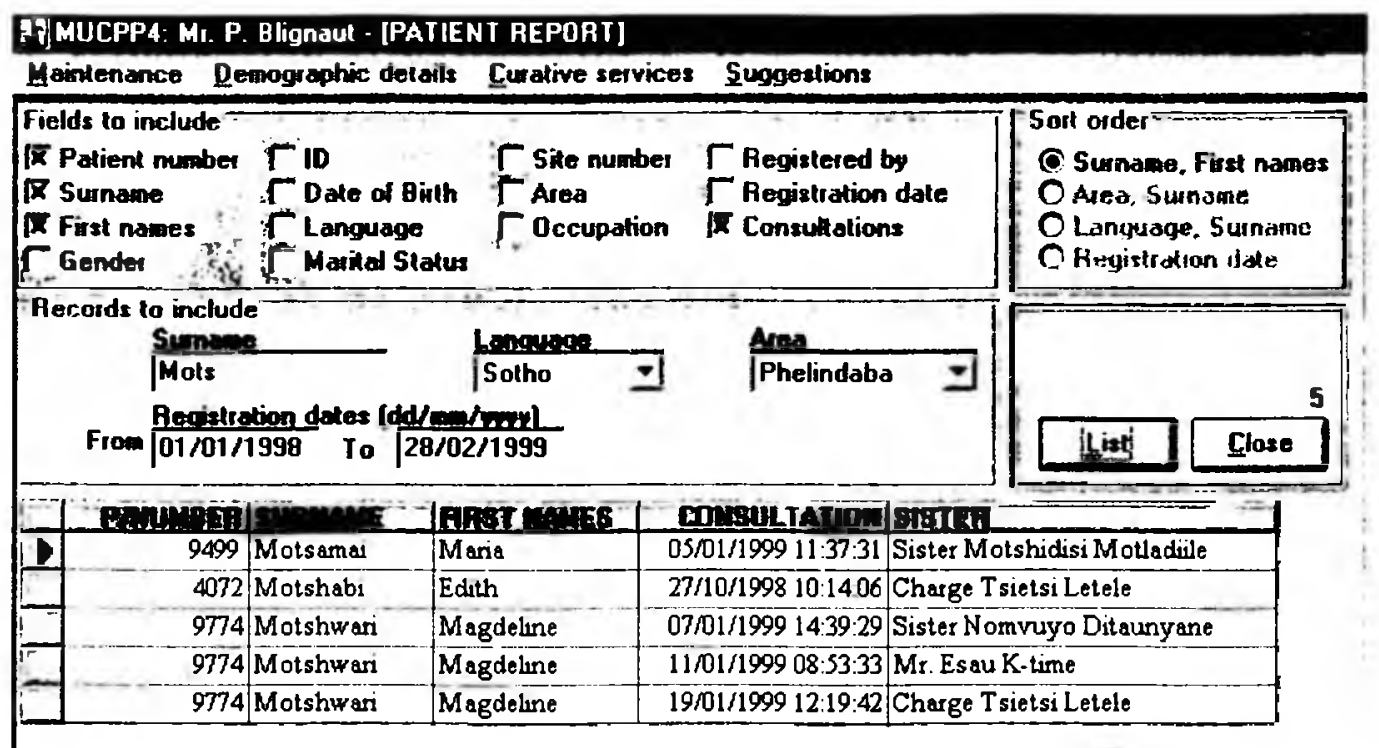

The system should make provision for different levels of access. Users should not be allowed to use the system without having to $\log$ on with a user name and password. Only selected users should be able to update definitions, enter new stock or register users. Clerical users should not be able to read data on medical interventions. Service providers should not be able to update entries made by another service provider. It should be possible to connect any entry to a specific user and date/time entered. An example of such a report is shown in figure 10.

The computerised system should replace the manual system with regard to the way of data capturing and reporting only. The system of folders for each patient should therefore not be abandoned. The continued availability of hard copies of medical interventions is essential to ensure that it is possible to revert back to the manual system in cases of power failure or other system failures. The computerised system should therefore automatically generate a hard copy of every consultation. A proper filing system for these printouts should be in place. In the current study, all intervention reports were printed to the dispensary. Upon acquiring their medicine from the chemist, the chemist took patients' folders, put the printouts inside and sent the folders back to the reception office where they were kept until the next visit.

If one workstation can be used by more than one service provider, for example in different shifts, it is essential to ensure that a user is not allowed to work in the name of another. A user's password is similar to his signature in the sense that it identifies the responsible person for updates made to the database. In the current study, however, users found it frustrating to $\log$ on before every new entry due to the time that went into the action regularly. We solved the problem partly by forcing the users to log on again after periods of inactivity of $15 \mathrm{~min}$ utes or longer.

\section{User-related requirements General computer training and motivation}

A prototyping approach towards discovering system requirements would not be effective if the prototype users do not have the basic computer-literacy skills. In the current study the users were trained in a word-processing package prior to implementation of the first prototype. This approach proved to be highly successful since the users were able to handle the keyboard and mouse without being afraid of the computer at the time when the first prototype was installed.

Computer users do not necessarily become more and more positively inclined toward the use of computers as they gain experience [Henderson, et. al., 1996:192; Marasovic et. al. 1997:96; Packer, 1988:102]. In previous studies it was found that a novice or first-time user could take 3-6 months to become more efficient (i.e. spend less time on data capturing) with the computer than was the case with the manual system

[Blignaut, 1999:182]. Continuous support and motivation along with the secondary spin-offs such as eliminating manual statistical processing and stock control motivated the clinic staff to persevere through this period.

\section{System specific training and support}

In an earlier study [Blignaut, 1996:33] a prototype was installed in several pilot sites. The users were trained in a single halfhour session and were left on their own thereafter. It was found that users do not use the computer if the researcher does not show continuous involvement.

In the current study, one of the clerical workers showed a keen interest in the research project. This person was then trained to act as on-the-spot system manager. This person had access rights to register new users, maintain the system configuration and update the contents of lists when necessary. He was also responsible for daily backups of the database. Most importantly, this person was available on a permanent basis to support users continuously, train new employees and attend to basic day-to-day problems. Users should never feel that they have been left in the lurch. Frustrated users are inefficient users. It was found that users preferred that system-specific training be done on a one-to-one basis. The users gained confidence while working with the system in an actual consultation. Trainers should be patient and friendly with users trainers should never sound irritated.

Although the prototypes used in the current system did not dispose of the facility, the need was experienced for a contextual on-line help facility to guide inexperienced users through the system. A training package that exactly mimics the operational system could also be very helpful. Such a package should include a training database that can be used for training users without any effect on the operational database.

\section{User-interface requirements}

Because of the approach of prototyping, it happened quite often in the current study that the user-interface was changed to accommodate new or changed functional requirements. It was found that users welcomed changes to the user-interface if it facilitated better control, saved time or solved a problem. Changes for the sake of experimenting were accepted less positively and had to be motivated very well. After four months of 


\section{Figure 11 : Typical layout of a consultation room}

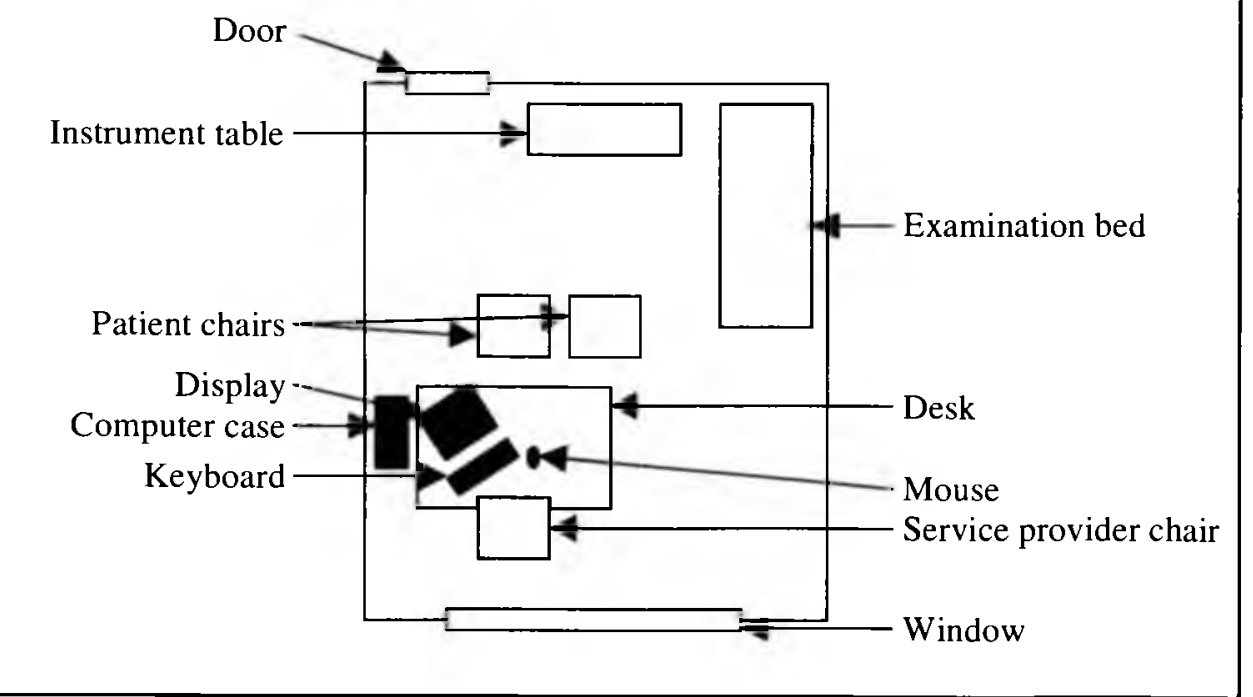

weekly changes to the interface, the users became irritated and explicitly asked that the experimenting must stop.

I was also clear that it was crucial to pay special attention to user-interface design, despite the fact that it was only prototype systems. It became evident that it would be difficult to motivate users to use a full-scale system after they struggled to work with a prototype with a badly designed user interface.

\section{Nurses' workload}

In the current study, the researchers tried to be sympathetic towards nurses' workload. New versions of the prototype were time and again implemented in parallel with the previous version. In order not to put pressure on users in times of peak workload, users had the option to still use a previous version with which they were more conversant. It is important to ensure that use of the prototype does not cause an increased workload. This approach proved to work well to ensure the continued positive collaboration of users.

\section{The workplace}

Physical abilities and limitations play an important role in the design of the workplace or workstation. Workplace design is important in ensuring job satisfaction, high performance and low error-rates [Dix, 1998:111; Shneiderman, 1998:20].

There should be enough desk space for documents and instruments. The monitor should not obscure eye contact with the patient and should be placed in such a way that there is no glare on the display. The chair should be comfortable, though easy to manoeuvre - the service providers normally get up from their chairs to examine a patient more than once during a consultation. The height and angles of chairs, work surfaces and displays should be adjustable.

Service providers should not be forced to sit too close to the screen. The user-interface should have large enough fonts to be readable also while standing at a distance of $2 \mathrm{~m}$ from the display. The consultation rooms should be well lit.

Figure 11 shows the layout of a typical consultation room in the current study. If there was glare on the display and also for the sake of privacy the curtains were kept closed throughout the day. This, of course, meant that the light had to be switched on to ensure adequate lighting.

\section{Summary}

The following points are proposed as specific aspects to take into account when developing and implementing a computerised patient-record system for primary health care in an urban township clinic:

- The data set should comprise all the essential elements without being too comprehensive.

- The system should support the existing daily business processes and not force the users to adapt their working habits.

- Users should be involved in the development and

implementation. A good working relation with users is essential to ensure users' goodwill and tude.

positive atti-

- Users should be trained in basic computer skills prior to implementation of a patient record information system.

- Users should be introduced gradually into the computerised system - the manual system should not be aban- doned at once. Users should be granted at least three of productivity that months to achieve the same level they could manage with the manual system.

- $\quad$ The system should fulfil the minimum functional requirements such as patient registration, recording of medical interventions, capturing and processing of statistics and stock control.

- $\quad$ The system should fulfil the minimum non-functional requirements such as connectivity, response times and safety and security.

In order to convince the advocates of the traditional paperand-pen-systems to change to computer technology, these aspects should be regarded as serious. We are dealing here with people who can be very good nurses but who are not necessarily devoted to computer use. If the introduction of computers does not have a considerable advantage over the manual system that has proved itself over years of experience and evolution, the service providers might be negatively inclined with a resultant loss of job satisfaction and even accuracy of data-capture and statistics. 


\section{References}

ADDERLEY,RN; HYDE, C \& MAUSETH,P 1997 : The Computer Age Impacts Nurses. Computers in Nursing. 15(1): 4346.

ANDERSON, JG; AYDIN, CE \& KAPLAN, B 1995 : An analytical framework for measuring the effectiveness/impacts of computer-based patient record systems. Proceedings of the 28th Annual Hawaii International Conference on Svstem Sciences. pp767-775.

BLIGNAUT, PJ 1996 : A comparison of different approaches towards computerisation of primary health care in the Free State. M.Sc. Dissertation. University of the Orange Free State.

BLIGNAUT, PJ 1999 : Usability of a computerised patient record system in a busy township primary health care clinic: A feasibility study. Ph.D. thesis. University of the Orange Free State.

BLIGNAUT, PJ \& MC DONALD, T 1997(1) : A computerised implementation of a minimum set of health indicators. Methods of Information in Medicine. 36(2): 122-126.

BLIGNAUT, PJ \& MC DONALD, T 1997(2) : To buy or develop: Software for primary health care. CHASA Journal of Comprehensive Health. 8(1): 27-30

DIX AJ; FINLAY JE; ABOWD GD \& BEALE, R 1998 : Human-Computer Interaction. Prentice Hall Europe, Second edition.

HENDERSON, RD \& DEANE, FP 1996 : User Expectations and Perceptions of a Patient Management Information System. Computers in Nursing. 14:188-193.

HETTINGER, BJ \& BRAZILE, RP 1992 : A Database Design for Community Health Data. Computers in Nursing. 10:109114.

LESKE, JS \& WERLEY, HH 1992 : Use of the Nursing Minimum Data Set. Computers in Nursing. 10:259-263.

MANDIL, SH 1995 : The choice of the national health care management information system component of the new NHIS/ SA. World Health Organisation. Technical report WHO/AOI/ 95.11 .

MANNING, J \& MCCONELL EA 1997 : Technology Assessment: A Framework for Generating Questions Useful in Evaluating Nursing Information Systems. Computers in Nursing 15:141-146.

MARASOVIC,C; KENNEY,C; ELLIOTT,D\&SINDHUSAKE, D 1997 : Attitudes of Australian nurses toward implementation of a clinical information system. Computers in Nursing. 15(2): 9l-98.

MCDONALD, T \& BLIGNAUT, PJ 1998 : A Comparison of a Manual and a Computer System in a Primary Health Care Clinic. Curationis. 21(3): 8-13.

NEAME, RLB 1995 : Electronic medical records. New Zea- land: Ministry of Health, New Zealand Health Information Service. 1995.

PACKER, CL 1988 : Nurses view computers as both friends and foes. Hospitals. 60(22): 101-102.

PULLIAM, L 1992 : A microcomputer-based information system for a nurse managed clinic. Computers in Nursing. 10:121-129.

SHNEIDERMAN, B 1998 : Designing the User Interface: Strategies for Effective Human-Computer Interaction. Third edition. Addison Wesley.

SOMMERVILLE, I 1995 : Software Engineering. Fifth Edition. Addison-Wesley, England.

SORRENTINO, EA 1991 : Overcoming the barriers to automation. Nursing Forum, 26:21-23.

VAN VUUREN, MVJ; STANDER, DCH \& DU TOIT, PW 1997 : Clinical assessment for the primary care practitioner. Department of Family Medicine, University of the Orange Free State. Unpublished.

Wallace, S 1994 : The computerised patient record. Bvte Magazine. 